This item was submitted to Loughborough's Research Repository by the author.

Items in Figshare are protected by copyright, with all rights reserved, unless otherwise indicated.

\title{
Levels of depression in transgender people and its predictors: Results of a large matched control study with transgender people accessing clinical services
}

\section{PLEASE CITE THE PUBLISHED VERSION}

https://doi.org/10.1016/j.jad.2018.02.051

\section{PUBLISHER}

(C) Elsevier

\section{VERSION}

AM (Accepted Manuscript)

\section{PUBLISHER STATEMENT}

This work is made available according to the conditions of the Creative Commons Attribution-NonCommercialNoDerivatives 4.0 International (CC BY-NC-ND 4.0) licence. Full details of this licence are available at: https://creativecommons.org/licenses/by-nc-nd/4.0/

\section{LICENCE}

CC BY-NC-ND 4.0

\section{REPOSITORY RECORD}

Witcomb, Gemma, Walter P. Bouman, L. Claes, Nicola Brewin, John R. Crawford, and Jon Arcelus. 2018. "Levels of Depression in Transgender People and Its Predictors: Results of a Large Matched Control Study with Transgender People Accessing Clinical Services". Loughborough University. https://hdl.handle.net/2134/31994. 
Levels of depression in transgender people and its predictors: Results of a large matched control study with transgender people accessing clinical services.

Gemma L. Witcomb ${ }^{1}$, Walter Pierre Bouman², Laurence Claes ${ }^{3,4}$, Nicola Brewin², John R. Crawford ${ }^{5}, \&$ Jon Arcelus ${ }^{2,6}$.

${ }^{1}$ School of Sport, Exercise, and Health Sciences, Loughborough University, Loughborough, United Kingdom

${ }^{2}$ Nottingham Centre for Transgender Health, Nottingham, United Kingdom

${ }^{3}$ Faculty of Psychology and Educational Sciences, KU Leuven, Leuven, Belgium

${ }^{4}$ Faculty of Medicine and Health Sciences (CAPRI), University of Antwerp, Antwerp, Belgium

${ }^{5}$ School of Psychology, University of Aberdeen, Aberdeen, United Kingdom

${ }^{6}$ Institute of Mental Health, Faculty of Medicine \& Health Sciences, University of Nottingham, Nottingham, United Kingdom

Corresponding author: Dr Walter Pierre Bouman, Nottingham Centre for Transgender Health, 12 Broad Street, Nottingham NG1 3AL, United Kingdom; Tel. +44 115 8760160; Fax: +44 115 8760160; E-mail: walter.bouman@doctors.org.uk 


\section{Abstract \\ Background}

Depression is a serious disorder which significantly impacts wellbeing and quality of life. Studies exploring mental wellbeing in the transgender population are mostly limited by small, non-homogenous samples and lack of matched controls. This study aimed to address these limitations and explore depression rates in a large sample of transgender people, compared with matched controls from the general population, as well as factors predicting depression in those taking cross-sex hormone treatment (CHT) compared to those not.

\section{Methods}

Transgender individuals $(n=913)$ completed a measure of depression, measures which predict psychopathology (self-esteem, victimization, social support, interpersonal problems), and information regarding $\mathrm{CHT}$ use. Participants were matched by age and experienced gender with adults from the general population who had completed the measure of depression.

\section{Results}

Individuals were categorized as having no, possible or probable depressive disorder. Transgender individuals not on $\mathrm{CHT}$ had a nearly four-fold increased risk of probable depressive disorder, compared to controls. Older age, lower self-esteem, poorer interpersonal function and less social support predicted depressive disorder. Use of CHT was associated with less depression.

\section{Limitations}

Participants were attending a national gender identity service and therefore represent only a sub-group of transgender people. Due to the cross-sectional design, 
longitudinal research is required to fully confirm the finding that $\mathrm{CHT}$ use reduces depression.

\section{Conclusion}

This study confirms that non-treated transgender individuals have an increased risk of a depressive disorder. Interventions offered alongside gender affirming treatment to develop interpersonal skills, increase self-esteem and improve social support may reduce depression and prepare individuals for a more successful transition.

Key words: Transgender; depression; self-esteem; social support; interpersonal function; cross-sex hormone treatment 


\section{Introduction}

Depression is one of the most commonly diagnosed mental disorders (Kessler et al., 2012) and one of the most intensely researched. Recent estimates suggest that depression affects around 350 million people globally and is one of the leading cause of disability worldwide (WHO, 2016). Efficaciousness of treatments (NICE, 2009) as well as identification of co-morbid disorders (such as anxiety, obsessivecompulsive disorder, and substance abuse), has led to a better understanding of this mental disorder. Depression has been found to be associated with a number of cooccurring factors, such as age (Stordal et al., 2003), being female (Girgus et al., 2017; Kessler, 2003), experiencing victimization (Collier, 2013), having less social support (Paykel, 1994), lower self-esteem (Sowislo \& Orth, 2013) and poorer interpersonal functioning (Barrett \& Barber, 2007; McFarquhar et al., 2018). As a result, some populations may be more at risk than others.

Indeed, depression has been found to be more prevalent in the LGBTQ (Lesbian, Gay, Bisexual, Transgender and Questioning) population compared to the general population (Marshal et al., 2011). It has been hypothesized that vulnerability to develop depression in the LGBTQ population relates to the stress experienced by this group. The Minority Stress model (Meyer, 1995) suggests that this can largely be explained by stressors induced by a hostile, homophobic, trans phobic culture, which often results in a lifetime of harassment, abuse, victimization, and discrimination (Meyer et al., 2008). However, in many studies that have explored the mental health of LGBT individuals, the samples have predominately consisted of LGB individuals, and have included very small numbers of transgender people (Haas et al., 2010; Walls et al., 2010). Thus, the prevalence, seriousness, and comorbidity 
of depression in the transgender population is still poorly researched and understood.

Transgender individuals are those whose gender identity does not match the sex assigned at birth (Bouman \& Arcelus, 2017). Some may present themselves in a way that is not within the traditional binary dichotomy of man/woman (Warren et al., 2016; Richards et al., 2016). A number of transgender people will choose to use cross-sex hormone treatment $(\mathrm{CHT})$ and/or gender affirming surgery to feminize or masculinize their bodies (Richards et al., 2016). Although recent systematic reviews have found that prevalence rates of transgender people is not high (Arcelus et al., 2015), most studies are limited by focusing on those attending services. Recent population studies indicate a clear increase in the number of transgender people in society (Arcelus et al., 2015; Flores et al., 2016; Kuyper \& Wijsen, 2014) and evidence of this is the increase in prevalence rates of transgender individuals presenting to specialist transgender health services in western countries (Arcelus et al., 2015; Collin et al., 2016). Recent studies have found that $0.6 \%$ of the American population is described as transgender (Flores et al., 2016). Population studies in the Netherlands and Belgium show similar results (Kuyper \& Wijsen, 2014; Van Caenegem, 2015). Transgender people describe personal struggles with coming out and disclosing their gender identity (Bockting \& Coleman, 2016), with many experiencing discrimination and victimization (Adams et al., 2016; Bockting et al., 2014; Claes et al., 2015), including rejection from family and others (Koken et al., 2009).

It is, therefore, not surprising that transgender people are reported to suffer from a high prevalence of mental health problems, most notably anxiety and depression 
(Bockting et al., 2013; Bouman et al., 2016; Davey et al., 2014; Dhejne et al., 2016; Heylens et al., 2014; Hoffman, 2014; Millet et al., 2016), low self-esteem (Erich et al., 2010), self-harm (Davey et al., 2016; Marshall et al., 2016) and disordered eating and poor body image (van de Grift, 2016a, 2016b; Witcomb et al., 2015). Previous research with cross-sectional data has found that transgender individuals have high levels of anxiety; higher than found in other groups or normative data (Bouman et al., 2016a).

In relation to depression, while the number of studies are limited, those that have been carried out report associations between depression and frequent experiences of discrimination in employment and housing, sexual violence, physical and verbal abuse, societal harassment related to gender presentation, a perceived need to keep one's transgender identity a secret, higher levels of minority stress and lower levels of social support [e.g., Bazargan \& Galvin, 2012; Bockting et al., 2014; Bouman et al., 2016b; Clements-Nolle et al., 2006; Huffaker \& Kwon, 2016; Leppel, 2016; McNeil et al., 2012; Nemoto et al., 2011). Hoffman (2014) recently reviewed the literature on depression in transgender women and reported that interactions with other people both positive via social support and negative via discrimination and abuse - are important predictors of depression.

Given that depression may be related to pre-transition problems or the transition itself, many studies have compared prevalence of depression between individuals who have and have not received gender affirming medical treatment (i.e., either cross-sex hormone treatment (CHT) or CHT and gender affirming surgery (GAS) (Bouman et al., 2016b; Colizzi et al., 2014; Davis \& Colton Meier, 2014; De Vries et al., 2014; Gómez- 
Gil et al., 2012; Heylens et al., 2014; Colton Meier et al., 2011) in order to try to ascertain whether depressive symptomology is alleviated by such interventions. Although the majority of these studies show that transgender people not on $\mathrm{CHT}$ experience higher levels of depressive symptomatology than those on treatment (Colizzi et al., 2014; Davis \& Colton Meier, 2014; De Vries et al., 2014; Gómez-Gil et al., 2012; Heylens et al., 2014; Colton Meier et al., 2011), the results are not consistent [e.g., Reisner et al., 2015). Indeed, the association between CHT and depression is likely to be influenced by stigma (felt and enacted) (Bockting et al., 2013) which may not always be lessened by receiving cross-sex hormone treatment or gender affirming surgery, nor may be wanted by all transgender people (Beek et al., 2015).

While these studies begin to paint a picture of the prevalence of depressive symptomology in the transgender population, there are a number of methodological limitations in the findings of the aforementioned studies. Firstly, the studies often include a non-heterogeneous group of transgender people, for example, those at different stages of transition (e.g., Bockting et al., 2014). This is the case for the studies exploring the use of the $\mathrm{CHT}$ and may go some way to explain the inconsistencies found. Transition stage is a crucial variable as those people further through their journey may have developed increased resilience over time and increased social support and affirmation of their gender identity (Bockting \& Coleman, 2016). This is therefore likely to be an important variable that needs to be considered and controlled for when exploring aspects of mental health and wellbeing in the transgender population. Secondly, while some have used comparison groups, which provide a degree of control, none of these studies have used matched control data to control for known factors that affect depression symptoms, such as age and gender (Arbus et al., 
2014; Baxter et al., 2013). Finally, studies most often tend to involve small samples sizes which may undermine reliability (Button et al., 2013).

To address the aforementioned limitations of small sample size, lack of matched control groups and non-homogeneity, the current study aimed to recruit a large cohort of adult transgender individuals, all at the same stage of accessing clinical services, and to compare them to a large cohort of adults recruited from the general population, matched by age and (experienced) gender. The study had three aims. Firstly, to determine the levels of depressive symptomatology suggesting no, possible and probable depressive disorder in non-treated transgender people accessing treatment (thereby excluding any transgender person who may already be on cross-sex hormones) and to compare them with a cisgender (person whose gender identity corresponds with their birth sex) matched sample from the general population. Secondly, to investigate the predictive role of variables known to be associated with depressive symptoms (age, assigned gender, self-esteem, social support, interpersonal function, and victimisation, and the use of $\mathrm{CHT}$ ). Finally, to investigate differences in depressive scores between transgender people on cross-sex hormone treatment $(\mathrm{CHT})$ with those not on cross-sex hormone treatment (non-CHT).

Based on the literature on depression in the transgender population it was hypothesized that levels of depression will be higher in the transgender population compared to the general population, and will be associated with older age, decreased self-esteem and social support, discrimination, lower levels of interpersonal function and lack of $\mathrm{CHT}$ treatment. No prediction was made regarding potential differences between transgender males and females. Physiological evidence points towards a 
possible genetic aetiology for depression which might manifest in differences based on birth assigned gender (e.g., Bangasser et al., 2016), while more social explanations may predict differences based on levels of hardship and discrimination experienced (expected to be higher for both cis and transgender women).

\section{Methods}

\subsection{Participants and Procedures}

\subsubsection{Transgender participants}

The sample consisted of all individuals $(n=1069)$ invited for assessment at a national transgender health service in the United Kingdom (UK) during a 3-year period from November 2012 to October 2015, who self-identified as transgender. Prior to the clinical assessment every patient was sent a questionnaire pack, consisting of the standard demographic and history questionnaires required as part of routine care, as well as the study questionnaires, an information sheet and consent form. If consent was given, participants returned all of the questionnaires by mail, in the envelope provided. If consent was not given, participants returned only the standard questionnaire. The refusal/non-response rate was $2.3 \%$. The study received ethical approval from the NHS Ethics committee and from the Research and Development Department from the Nottinghamshire Healthcare NHS Foundation Trust in line with Health Research Authority guidance (Health Research Authority, 2013). For the first aim of the study, in order to have a homogenous group, only those individuals who were not on any cross-sex hormones (non-CHT) before assessment were eligible to be included in this analysis. For the second and third aims, the full sample was included. 


\subsubsection{Control group}

A sample of 3816 male and female adults from the general UK population who were recruited between 2006 and 2009 for a different study (Crawford, 2009) were used as controls and matched by age and gender to the transgender sample. The normative data of the control sample was purposefully broad, having selected a wide representation of the general adult UK population, in terms of age, education, and gender (although, in most cases, females were over sampled). Participants were recruited from a variety of sources, including both large and small businesses, public service organizations, community centres, and recreational groups. Both urban/ suburban and rural-semi-rural locations were represented in the sample, although recruitment was greater in the former locations. Participants were invited to complete the Hospital Anxiety and Depression Scale (Zigmond \& Snaith, 1983) and, if they consented, to return completed questionnaires in a sealed envelope. The questionnaires were filled out anonymously. The combined refusal/non-return rates ranged from approximately $17 \%$ to $21 \%$. Ethical approval for this study and the previous studies had been obtained from the Psychology Ethics Committee of the University of Aberdeen, Aberdeen, United Kingdom.

\subsection{Main Outcome Measures}

2.2.1. The Hospital Anxiety and Depression Scale (HADS) (Zigmond \& Snaith, 1983) is a 14-item self-report screening scale that was originally developed to indicate the possible presence of anxiety and depression states in the setting of a medical nonpsychiatric outpatient clinic. The HADS consists of two subscales, HADS-Anxiety (HADS-A) and HADS-Depression (HADS-D). For this study only the subscale of 
depression will be used. This subscale has seven items, rated on a 4-point Likert scale (ranging from, as much as I always do (0); not quite so much (1); definitely not so much (2); to not at all (3)), indicating symptoms of depression during the preceding week. A score of 0-7 on either scale is regarding as being in the non-clinical range (no symptoms), a score of 8-10 is suggestive of the presence of a depressive disorder (possible symptoms), and a score of 11 or higher indicates the probable presence of a depressive disorder (symptoms). Maximum subscales scores are 21. The HADS was found to perform well in assessing the symptom severity and caseness of depressive disorders in both somatic, psychiatric and primary care patients and in the general population (Bjelland et al., 2002) and it has been previously used with transgender individuals (Colizzi et al., 2014; Gómez-Gil et al., 2012). A number of researchers have explored HADS data to establish the cut-off points for caseness of depression and a systematic review of a large number of studies identified a cut-off point of 8/21 for depression (Bjelland et al., 2002). For depression (HADS-D) this gave a specificity of 0.7 and a sensitivity of 0.9 . In this study, the Cronbach's alpha was 0.76

2.2.2. The Rosenberg Self-Esteem Scale (RSE) (Rosenberg, 1965) is a self-report measure of global self-esteem. Items are rated on a 4-point rating scale ranging from 0 ('Strongly disagree') to 3 ('Strongly agree'). Its total score is calculated by summing the item scores with higher scores indicating higher self-esteem. The RSE has been empirically validated and administered previously to transgender individuals (Arcelus et al., 2016; Vocks et al., 2009). In this study, the Cronbach's alpha was 0.91 . 
2.2.3. The Experiences of Transgender Phobia Scale (Lombardi et al., 2001) assesses experiences of discrimination or victimization on the basis of gender identity or gender presentation. The questionnaire was based on the Transgender Violence Study and measured people's lifetime experiences of violence and harassment and experiences of any form of economic discrimination as a result of being transgender (e.g., verbal abuse, physical abuse, fired from a job, problems getting a job, and problems getting health or medical services due to gender identity or presentation). All five items are to be rated on a four-point Likert scale ranging from 0 ('never') to 3 ('several times'). This scale has been previously used with transgender individuals (Arcelus et al., 2016; Bouman et al., 2016c; Claes et al., 2015; Colizzi et al., 2014). In this study, the Cronbach's alpha was 0.59.

2.2.4. The Multidimensional Scale of Perceived Social Support (MSPSS) (Zimet et al., 1990) is a 12-item, self-report scale designed to tap social support from family, friends, and significant others. Items are rated on a 7-point Likert scale ranging from 1 ('very strongly agree') to 7 ('very strongly disagree'). The instrument includes three subscales to address these three types of support (family, friends, significant others). The mean total and subscale scores range from 1 to 7 , and a higher score indicates greater perceived social support. This scale has recently been used in transgender populations (Boza \& Perry, 2014; Davey et al., 2014). In this study, the Cronbach's alpha was 0.89 .

2.2.5. The Inventory of Interpersonal Problems (IIP-32) (Barkham, Hardy \& Startup, 1996) measures interpersonal difficulties. It consists of 32 items to be rated on a 5point Likert scale ranging from 0 ('Not at all') to 4 ('Extremely'). There are eight 
subscales of interpersonal problems: Hard to be Assertive, Hard to be Sociable, Hard to be Supportive, Hard to be Involved, Too Dependent, Too Caring, Too Aggressive, and Too Open. A total mean score provides a global measure of interpersonal distress. Higher subscale scores indicate greater interpersonal difficulties. The IIP-32 is a shortened version of the original IIP, yet the psychometric properties are retained; a confirmatory factor analysis demonstrated high reliability with alpha coefficients of 0.70 to 0.88 (Barkham et al., 1996). The IIP-32 has been successfully used in both non-clinical (Berry et al., 2006) and clinical samples (Bouman et al., 2016c, Davey et al., 2015]. In this study, the Cronbach's alpha was 0.87 .

\subsection{Data Analysis}

All quantitative data analyses were performed by means of SPSS 22 (IBM, 2013). Based on HADS-D scores, individuals were grouped into one of three categories: 1) people with no depressive disorder, 2) people with symptoms suggesting of a possible depressive disorder and, 3) people with symptoms suggesting a probable depressive disorder. For Aim 1, only transgender people not on cross-sex hormones were included in order to have a homogenous group. Both groups will be matched according to age and experienced gender. As the control group identified themselves based on the binary notion of gender (male and female), in order for the matching to be possible only transgender people who identified as male or female will be selected. Transgender non-binary people will not be included. The chi-square test statistic was used to compare the frequency with which transgender and general population adults fell into each of the three depressive symptomology categories (no, possible, or probable depressive disorder). For the remaining aims, all transgender individuals were included. For Aim 2, a binary logistic regression analysis was performed to 
explore the predictive value of the other measures of psychopathology, wellbeing, and hormone use on the presence/absence of depressive symptomology. For Aim 3, frequency of inclusion in each depressive symptomology category was compared between transgender people on cross-sex hormones and those not on cross-sex hormones using the chi-square test statistic. The level of significance for all analyses was set at $p<0.05$. See Figure 1 for an illustration of the cohorts for each aim and the exclusions.

(Insert Figure 1. about here)

\section{Results}

3.1. Socio-demographic characteristics of the transgender sample

The age range of the 1069 transgender individuals invited to participate was 15-79 years with a mean age of 30.4 years $(S D=13.9)$. Of these, $25(2.3 \%)$ did not consent and a further 131 participants (12\%) identified themselves as non-binary (i.e., not identifying with either an exclusive male or female identity) and so were excluded from the analysis. Of the remaining 913 participants, 582 (63.7\%) participants identified themselves as transgender females (assigned male at birth) and 331 (36.3\%) as transgender males (assigned female at birth). Of the total sample of 913 transgender people, 638 (69.9\%) were not on cross-sex hormone treatment and 261 (28.9\%) were on cross-sex hormone treatment. Fourteen patients had missing data, relating to either their use or not of cross-sex hormones $(14 ; 1.5 \%)$ leaving a final sample size of $(n=899)$. 
3.2. Aim 1: Comparative analyses between transgender people not on $\mathrm{CHT}$ and controls.

For the first aim of the study only people not on CHT were selected ( $n=638)$. The age range of this group was $16-79$ years with a mean age of 28.6 years $(S D=12.8)$. This group was matched by age and experienced gender with the control group. However, 46 (7.2\%; 18 transgender females and 28 transgender males aged 17 and 18 with an average age of 17.3 years $[S D=0.48]$ ) could not be matched due to insufficient numbers for that age in the control data. Therefore, this gave a final sample of 1184 participants; 592 non-CHT patients who were matched with 592 participants in the control population database. Taking these together, $436(36.8 \%)$ were transgender and cisgender females and 748 (63.2\%) were transgender and cisgender males.

In the category of 'No Depressive Disorder', the control group was significantly more prevalent than the transgender group. In contrast, the transgender group was significantly more prevalent in the categories 'Possible Depressive Disorder' and 'Probable Depressive Disorder' compared to the control group. This difference was statistically significant $\left[\mathrm{X}^{2}(2)=223,388, p<.001\right]$. Furthermore, when analysed separately by identified gender, the difference in prevalence remained statistically significant. That is, the control group was more prevalent in the 'No Depressive Disorder' category and the transgender group was more prevalent in the 'Possible Depressive Disorder' and 'Probable Depressive Disorder' categories in analyses that compared cisgender and transgender men $\left[X^{2}{ }_{(2)}=149.163 p<.001\right]$ and cisgender and transgender women $\left.\left[\mathrm{X}^{2}(2)=74.814, p<.001\right]\right)$.

(Insert Table 1. about here) 
3.3. Aim 2: Predictors of the presence/absence of depressive disorder (probable and possible) among the whole transgender population.

In order to explore the predictors of depression in the transgender population, the data from all of the transgender people were analyzed $(n=899)$. Those in the category of probable and possible depressive disorder were grouped together into one category (depressive disorder). Linear regression analysis was performed with the presence or absence of depressive disorder as the dependent variable, and age, gender, selfesteem, social support, interpersonal function and victimization and presence and absence of $\mathrm{CHT}$ as independent variables. The results showed that four of these variables were significant predictors for a transgender person attending a health service to suffer from a depressive disorder; higher age, lower social support, lower self-esteem, and greater interpersonal problems (See Table 2).

(Insert Table 2. about here)

3.4. Aim 3: Comparative analyses between transgender people on $\mathrm{CHT}$ and those not on $\mathrm{CHT}$.

Analyses comparing transgender people on $\mathrm{CHT}(n=261)$ with those not on CHT ( $n=638)$ found a statistically significant difference between the groups. There were more transgender people using $\mathrm{CHT}$ in the category of no depressive disorder 
compared to those not on $\mathrm{CHT}\left[\mathrm{X}^{2}(1)=11,556, p<.001\right]$. The latter group was more prevalent in the category depressive disorder (see Table 3.). A comparison of the pattern within each group found that for both transgender males and transgender females there were more transgender people in the depressive disorder category who were not on CHT compared to those who were (transgender females; $\left[\mathrm{X}^{2}{ }_{(1)}=6,709, p\right.$ $<0.05])$ and transgender males; $\left.\left[\mathrm{X}^{2}(1)=4,535, p<0.05\right]\right)$.

(Insert Table 3. about here)

\section{Discussion}

Depression is a common mental disorder. Globally, rates of depression are high and depression is associated with great disease burden and for this reason it is one of the conditions that is targeted by the WHO's Mental Health Gap Action Programme (WHO, 2016). While the precipitating factors are many and varied, certain groups may be at an increased risk of developing depressive symptomology. In line with this, this study found high rates of possible (13\%) and probable (11\%) depression in untreated treatment seeking transgender people attending a transgender health service in the UK. Overall, there was a significantly higher prevalence of transgender people reporting depressive symptomology than controls - an almost 4-fold increased risk and this pattern was evident when comparing both males (cis and trans) and females (cis and trans). Within the full transgender group (treated and untreated), older age, less social support, lower self-esteem, and greater interpersonal problems were significant predictors of depressive symptomology, and both transgender males and 
transgender females were more likely to be in the depressive disorder categories if they were not on cross-sex hormones.

While some mental health disorders, such as anxiety (McLean et al., 2011), posttraumatic stress disorder (Mendoza et al., 2016) and depression (Fellinger et al., 2018; Fisher et al., 2017) often present as more prevalent in females, with explanations linked to variations in the effects of sex hormones (e.g., estrogen and progesterone, corticotropin-releasing factor (CRF), and neurotransmitters such as serotonin) on the fight or flight response (Bangasser et al., 2016), which may vary across the menstrual cycle (Rohleder et al., 2001), here gender did not appear to differentiate between risk for depression. This suggests that the increased risk that transgender individuals appear to face may be more related to their experiences of being transgender, rather than their birth assigned physiology. Indeed, for transgender people in particular, the experience of minority stress [Meyer, 1995; 2003) is significant and likely plays a greater role (Davey et al., 2014).

Older age, less social support, lower self-esteem, and greater interpersonal problems were significant predictors of depressive symptomology in treated and untreated transgender people. These variables are often inextricably linked; those with little social support are likely to have reduced self-esteem and this may influence their interpersonal functioning. Or indeed poor interpersonal functioning may lead to difficulties in relationships which can lead to a limited social network on which one can rely on for support. Although in some circumstances individuals can develop coping mechanisms over time which can lead to reduction in depression (Nuttbrock et al., 2010), here depression was predicted by older age which may reflect the cumulative 
effect over the years of the other variables (i.e., longer period of lack of social support) or greater difficulties in coming out when older and experiencing transphobia as a more recent occurrence (Singh \& Bower, 2017). Identification of such predictor variables is important as it provides a richer insight into the experiences of transgender people. Rather than simply reporting that depression is higher, we seek to understand what factors might be associated with this, in order to develop ways to support transgender people. That is, to focus on the factors implicated in the development and maintenance of depression. In line with this, the finding that social support, selfesteem, and interpersonal problems are significant suggests that these could be valuable areas for clinicians to work on with their clients, in addition to addressing the presenting symptoms in the usual ways (therapy and/or pharmacological interventions) (McFarquhar et al., 2018). Interventions in other areas, with other client groups, have found effective ways to increase self-esteem (Fennell, 2006; Morton et al., 2012; Rigby \& Waite, 2007) and interpersonal psychotherapy (IPT) has been shown to improve interpersonal functioning (e.g., Arcelus et al., 2011; Hara et al., 2000; Mufson et al., 2013) and these could be easily translated to the transgender population. Delivering such interventions alongside facilitating peer support, either face-to-face or online, may be one way in which clinicians can assist in developing social support for their clients. Indeed, peer support can offer avenues to greater social connectedness, increased confidence and ability to challenge stigma in a safe space, insight into health decisions from hearing shared experiences, and potentially increased awareness of mental health struggles which may lead to increases in help seeking behavior (Naslund et al., 2016). 
Satisfaction with support also appears to be key (McNeil et al., 2012); i.e., quality not quantity. Indeed, being able to effectively utilize social support has been implicated in lower levels of depression in transgender women (Clements-Nolle et al., 2011) in contrast to more avoidant coping strategies) (Mepham et al., 2014) and therefore working with families to ensure that the support that is being given is serving the need of the transgender person, for example in increasing self-efficacy (Bouman et al., 2016b), may be valuable. Focusing on these factors may help to reduce transgender individuals' likelihood of experiencing depression, and/or increases in depression, when going through their transitional process.

The analysis comparing transgender individuals on cross-sex hormone treatment with those not on such treatment confirmed that there are apparent benefits to the use of hormones on depressive symptomology and reflects the benefits reported firsthand by clinicians and within the literature (Bouman et al., 2016b; Davis et al., 2014; De Vries et al., 2014; Gómez-Gil et al., 2012; Heylens et al., 2014), although these findings need to be replicated in longitudinal studies. This can be taken as further evidence to support the argument that early initiation of gender confirming treatment for transgender people is beneficial to the long term mental wellbeing of transgender individuals and that access to cross-sex hormones should be made available at the earliest possible point. Currently, many people resort to purchasing hormones via the internet which carries inherent dangers (Mepham et al., 2014). This is because the pathways to care within the UK are extremely prescriptive which serves to draw out the time taken to time to access hormones (Coleman et al., 2010; Wylie et al., 2014). This is in addition to already long waiting times to be seen by a specialist clinical service due to the limited number that exist and increasing numbers of referrals. 
Changes to the infrastructure and processes available would serve to help transgender individuals access hormone treatment earlier, if desired. However, due to the cross-sectional nature of this study, the direction of effect in unknown. That is, whether the positive impact on psychological wellbeing associated with the use of $\mathrm{CHT}$ is a consequence of starting the process of gender role transition, or whether those who start CHT before a specialist assessment do so because they have greater selfesteem, better interpersonal relationships and more social support - possibly from other trans friends who may guide them - and are therefore in a better position to embark on CHT without the assistance of a medical professional.

The global generalizability of these findings needs to be borne in mind. Waiting times in the UK are long (currently between 12-14 months) and the UK legislation on access to free healthcare for transgender people, as well as legislation such as the Gender Recognition Act 2004 and the Sex Discrimination (Gender Reassignment) Regulations Act 1999 and 2008, mean that the experiences of transgender people in the UK may be very different from that of trans people in other countries (Davey et al., 2015). These differences are further emphasized when considering how changes to diagnosis might affect access to care differently in different countries (Beek et al., 2016). Within the UK trans population, these results may only be generalizable to transgender individuals who have chosen to access care via transgender health services, which therefore fails to capture those who have yet to seek treatment (Zucker \& Lawrence, 2009). However, a major strength of this study and one which seeks to address methodological criticisms of past research (e.g., Dhejne et al., 2011) is the use of a matched control sample (transgender and controls matched on experienced gender; transgender on $\mathrm{CHT}$ and not on $\mathrm{CHT}$ ); a method we have used previously (Witcomb 
et al., 2015). Regarding sample size, this study is, to our knowledge, one of the largest studies in the field. It is worth noting, however, that $12 \%$ of the participants invited to participate identified themselves as being non-binary; identifying neither with their birth assigned gender, nor the opposite gender. These participants were excluded, so as to maintain homogeneity, since recent studies suggest that non-binary people may have poorer health than binary transgender people (Orre et al., 2017; Rimes et al., 2017; Warren et al., 2016; Zeluf et al., 2016). However, as the prevalence of people identifying as non-binary is increasing (Richards et al., 2016) it is possible that some of our transgender participants may ultimately endorse a non-binary gender as opposed to a binary transgender identity. Furthermore, our control population was not asked about their gender identity and so it is possible that this population may include some transgender and non-binary people. However, since the number of non-binary people seen within the service, as well as the prevalence of transgender individuals within the general population, is very low overall, this is unlikely to pose a major methodological concern. But, we do propose that in the future matching may be more accurate when done on the basis of birth assigned gender, and that binary and nonbinary transgender cohorts be included within studies together. Indeed, since our control group was taken from a general population sample, it may also be useful to compare depression rates in binary and non-binary trans people with control participants from both non-clinical and clinical populations to get a better picture of the rates of depression experienced.

Overall, this study highlights the need for clinical services to properly assess depressive symptomology, and associated predictor variables, in treatment-seeking transgender individuals and to expedite the use of cross-sex hormones, where 
appropriate, in order to improve mental health. Here, untreated transgender people had higher prevalence rates of possible or probable depressive disorder than controls and trans people already on cross-sex hormones. Higher age, lower self-esteem, lower social support and poorer interpersonal functioning all predicted depressive disorders. Focused interventions that primarily aim to increase self-esteem, social support and interpersonal functioning may prove to be useful in increasing the quality of life of transgender people. 


\section{References}

Adams, K.A., Nagoshi, C.T., Filip-Crawford, G., Terrell, H.K., Nagoshi, J.L., 2016. Components of gender-nonconformity prejudice. Int J Transgenderism.17(34),185-198.

Arbus, C., Hergueta, T., Duburcq, A., Saleh, A., Le Guern, M-E., Robert, P., Camus, V., 2014. Adjustment disorder with anxiety in old age: Comparing prevalence and clinical management in primary care and mental health care. Eur Psychiatry. 29,233-238.

Arcelus, J., Bouman, W.P., Witcomb, G.L., Van den Noortgate, W., Claes, L., Fernandez-Aranda, F., 2015. Prevalence of transsexualism: A systematic review and meta-analysis. Eur Psychiat. 30(6),807-815.

Arcelus, J., Claes, L., Witcomb, G.L., Marshall, E., Bouman, W.P., 2016. Risk factors for non-suicidal self-injury among trans youth. J Sex Med. 13(3),402-412.

Arcelus, J., Whight, D., Haslam, M., 2011. Interpersonal problems in people with bulimia nervosa and the role of interpersonal psychotherapy, in: Hay, P. (Ed.), New insights into the prevention and treatment of bulimia nervosa. InTech, Rijeka, pp.3-12.

Bangasser, D.A., Wiersielis, K.R., Khantsis, S., 2016. Sex differences in the locus coeruleus-norepinephrine system and its regulation by stress. Brain Res. 1641,177-188.

Barrett, M.S., Barber, J.P., 2017. Interpersonal profiles in major depressive disorder. J Clin Psychol. 63(3),247-66. 
Barkham, M., Hardy, G.E., Startup, M., 1996. The IIP-32: a short version of the Inventory of Interpersonal Problems. Br J Clin Psychol. 35,21-35.

Baxter, A.J., Scott, K.M., Vos, T., Whiteford, H.A., 2013. Global prevalence of anxiety disorders: a systematic review and meta-regression. Psychol Med. 43(5),897910.

Bazargan, M., Galvin F., 2012. Perceived discrimination and depression among low-income Latina male-to-female transgender women. BMC Public Health. 12, 663.

Beek, T.F., Cohen-Kettenis, P.T., Bouman, W.P., de Vries, A.L.C., Steensma, T.D., Witcomb, G.L., Arcelus, J., Richards, C., Elaut, E., Kreukels, B.P.C., 2016. Gender incongruence of adolescence and adulthood: Acceptability and clinical utility of the World Health Organization's proposed ICD-11 criteria. PLoS ONE. 11(10), e0160066.

Beek, T., Kreukels, B.P.C., Cohen-Kettenis, P.T., Steensma, T.D., 2015. Partial gender request and underlying motives of applicants for gender affirming interventions. J Sex Med. 12,2201-2205.

Berry, K., Wearden, A., Barrowclough, C., Liversidge, T., 2006. Attachment styles, interpersonal relationships and psychotic phenomena in a non-clinical student sample. Pers Individ Dif. 41,707-718.

Bjelland, I., Dahl, A.A., Neckelmann, T.T., 2002. The validity of the Hospital Anxiety and Depression Scale. An updated literature review. J Psychosom Res. 52,6977.

Bockting, W.O., Coleman, E., 2016. Developmental stages of the transgender coming out process, in: Ettner, R., Monstrey, S., Eyler, A., (Eds.), Principles of Transgender Medicine \& Surgery, $2^{\text {nd }}$ edition. New York, Routledge. 
Bockting, W.O., Miner, M.H., Swinburne Romine, R.E., Hamilton, A., Coleman, E., 2013. Stigma, mental health, and resilience in an online sample of the US transgender population. Am J Public Health. 103,943-951.

Bouman, W.P., Arcelus, J., 2017. The Transgender Handbook: A guide for transgender people, their families, and professionals. New York, NY: Nova Publishers.

Bouman, W.P., Claes, L., Brewin, N., Crawford, J.R., Millet, N., FernandezAranda, F., Arcelus, J., 2016. Gender dysphoria and anxiety: A comparative study between transgender people and the general population. Int J Transgenderism. 18(1), 16-26. DOI: 10.1080/15532739.2016.1258352

Bouman, W.P., Claes, L., Marshall, E., Pinner, G.T., Longworth, J., Maddox, V., Witcomb, G.L., Jimenez-Murcia, S., Fernandez-Aranda, F., Arcelus, J., 2016. Sociodemographic variables, clinical features and the role of pre-assessment cross-sex hormones in older trans people. J Sex Med. 13(4),711-719.

Bouman, W.P., Davey, A., Meyer, C., Witcomb, G.L., Arcelus, J., 2016 Predictors of psychological well-being among trans individuals. Sex Relation Ther. 31(3),357-373.

Boza, C., Perry, K.N., 2014. Gender-related victimization, perceived social support, and predictors of depression among transgender Australians. Int J Transgenderism. 15,35-52.

Button, K.S., Ioannidis, J.P., Mokrysz, C., Nosek, B.A., Flint, J., Robinson, E.S., Munafò, M.R., 2013. Power failure: why small sample size undermines the reliability of neuroscience. Nature Rev Neurosci. 14(5),365-376.

Claes, L., Bouman, W.P., Witcomb, G.L., Thurston, M., Fernandez-Aranda, F., Arcelus, J., 2015. Non-suicidal self injury in transsexualism: Associations with 
psychological symptoms, victimization, interpersonal functioning and perceived social support. J Sex Med. 12,168-179.

Clements-Nolle, K., Marx, R., Guzman, R., Katz, M., 2011. HIV prevalence, risk behaviors, health care use, and mental health status of transgender persons: implications for public health intervention. Am J Public Health .91(6),915-921.

Clements-Nolle, K., Marx, R., Katz, M., 2006. Attempted suicide among transgender persons: The influence of gender-based discrimination and victimization. J Homosex. 51,53-69.

Coleman, E., Bockting, W., Botzer, M., Cohen-Kettenis, P., DeCuypere, G., Feldman, J., ... Zucker, K., 2012. Standards of care for the health of transsexual, transgender, and gender-nonconforming people, Version 7. Int J Transgenderism. 13(4), 165-232.

Colizzi, M., Costa, R., Todarello, O., 2014 Transsexual patients' psychiatric comorbidity and positive effect of cross-sex hormonal treatment on mental health. Psychoneuroendocrinology. 39,65-73.

Collier, K.L., Van Beusekom, G., Bos, H.M.W., Sandfort, T.G.M., 2013. Sexual orientation and gender identity/expression related peer victimization in adolescence: A systematic review of associated psychosocial and health outcomes. J Sex Res. 50, 299-317.

Collin, L., Goodman, M., Tangpricha, V., 2016, in: Ettner, R., Monstrey, S., Eyler, A., (Eds.). Principles of Transgender Medicine \& Surgery, $2^{\text {nd }}$ edition. New York: Routledge.

Colton Meier, S.L., Fitzgerald, K.M., Pardo, S.T. and Babcock, J., 2011. The effects of hormonal gender affirmation treatment on mental health in female-to-male transsexuals. J Gay \& Lesbian Ment Health. 15(3), 281-299. 
Crawford, J.R., Garthwaite, P.H., Lawrie, C.J., Henry, J.D., MacDonald, M.A., Sutherland, J., Sinha, P., 2009. A convenient method of obtaining percentile norms and accompanying interval estimates for self-report mood scales (DASS, DASS-21, HADS, PANAS, and SAD). Br J Clin Psychol.48,163-180.

Davey, A., Arcelus, J., Meyer, C., Bouman, W.P., 2016. Self-injury among trans individuals in transition and matched controls: Prevalence and associated factors. Health Soc Care Comm. 24,485-494.

Davey, A., Bouman, W.P., Arcelus, J., Meyer, C., 2014. Social support and psychological wellbeing: A comparison of patients with gender dysphoria and matched controls. J Sex Med. 11,2976-2985.

Davey, A., Bouman, W.P., Arcelus, J., Meyer, C., 2015. Interpersonal functioning among individuals with gender dysphoria. J Clin Psychol. 71,1173-1185.

Davis, S.A., Colton Meier, S., 2014. Effects of testosterone treatment and chest reconstruction surgery on mental health and sexuality in female-to-male transgender people. Int J Sex Health. 26,113-128.

Dhejne, C., Lichtenstein, P., Boman, M., Johansson, A.L., Långström, N. and Landén, M., 2011. Long-term follow-up of transsexual persons undergoing sex reassignment surgery: cohort study in Sweden. PLoS ONE. 6(2), e16885.

Dhejne, C., Van Vlerken, R., Heylens, G., Arcelus, J., 2016. Mental health and gender dysphoria: A review of the literature. Int Rev Psychiat.28(1),44-57.

De Vries, A.L.C., McGuire, J.K., Steensma, T.D., Wagenaar, E.C.F., Doreleijers, T.A.H., Cohen-Kettenis, P.T., 2014. Young adult psychological outcome after puberty suppression and gender reassignment. Pediatrics. 134,696-704. 
Erich, S., Tittsworth, J., Kerstein, A.S., 2010. An examination and comparison of transsexuals of color and their white counterparts regarding personal well-being and support networks. J LGBT Fam Stud.6,25-39.

Girgus, J.S., Yang, K., Ferri, C.V., 2017. The gender difference in depression: Are elderly women at greater risk for depression than elderly men? Geriatrics. 2(4),35.

Fellinger, M., Waldhör, T., Blüml, V., Williams, N., Vyssoki, B., 2018. Influence of gender on inpatient treatment for bipolar disorder: An analysis of 60,607 hospitalisations. J Affect Disord. 225, 104-107.

Fennell, M., 2006. Overcoming low self-esteem: Self-help program. London: Constable \& Robinson.

Fisher, P.M., Larsen, C.B., Beliveau, V., Henningsson, S., Pinborg, A., Holst, K.K., \& ... Frokjaer, V.G., 2017. Pharmacologically induced sex hormone fluctuation effects on resting-state functional connectivity in a risk model for depression: A randomized trial. Neuropsychopharmacology. 42(2),446-453.

Flores, A.R., Herman, J.L., Gates, G.J., Brown, T.N.T., 2016. How many adults identify as transgender in the United States? Los Angeles, CA: The Williams Institute.

Gómez-Gil, E., Zubiaurre-Elorza, L., Esteva, I., Guillamon, A., Godas, T., Cruz Almaraz, M., Halperin, I., Salamero, M., 2010. Hormone-treated transsexual report less social distress, anxiety, and depression. Psychoneuroendocrinology. 37,662-670.

Haas, A.P., Eliason, M., Mays, V.M., Mathy, R.M., Cochran, S.D., D’Augelli, A.R., Silverman, M.M., Fisher, P.W., Hughes, T., Rosario, M., Russell, S.T., 2010. Suicide and suicide risk in lesbian, gay, bisexual, and transgender populations: Review and Recommendations. J Homosex. 58, 10-51. 
Hara, M.W.O., Stuart, S., Gorman, L.L., Wenzel, A., 2000. Efficacy of interpersonal psychotherapy for postpartum depression. Arch Gen Psychiatry, 57,1039-1045.

Health Research Authority (HRA), 2013. Guidance for NHS Research Studies. London: Health Research Authority.

Heylens, G., Verroken, C., De Cock, S., T'sjoen, G., De Cuypere, G., 2014. Effects of different steps in gender reassignment therapy on psychopathology: a prospective study of persons with a gender identity disorder. J Sex Med. 11(1),119126.

Hoffman, B., 2014. An overview of depression among transgender women. Dep Res \& Treat. 2014. Article ID 394283. DOI.org/10.1155/2014/394283

Huffaker. L., Kwon, P., 2016. A comprehensive approach to sexual and transgender prejudice. J Gay Lesbian Soc Serv. 28(3),195-213.

IBM Corporation (2013). IBM SPSS Statistics for Windows. Version 22.0. Armonk, NY: IBM Corporation.

Kessler, R.C., 2003. Epidemiology of women and depression. J Affect Disord. 74(1), 5-13.

Kessler, R.C., Petukhova, M., Sampson, N.A., Zaslavsky, A.M. and Wittchen, H.U., 2012. Twelve-month and lifetime prevalence and lifetime morbid risk of anxiety and mood disorders in the United States. Int J Method Psych. 21,169-184.

Koken, J., Bimbi, D.S., Parsons, J.T., 2009. Experiences of familial acceptancerejection among transwomen of color. J Fam Psychol. 23,853-860.

Kuyper, L., Wijsen, C., 2014. Gender identities and gender dysphoria in the Netherlands. Arch Sex Behav. 43,377-385. 
Leppel, K., 2016. The labor force status of transgender men and women. Int J Transgenderism. 17(3-4),155-164.

Lombardi, E.L., Wilchins, R.A., Priesing, D., Malouf, D., 2001. Gender violence. J Homosex. 42,89-101.

Marshall, E., Claes, L., Bouman, W.P., Witcomb, G.L., Arcelus, J., 2016. Nonsuicidal self-injury and suicidality in trans people: a systematic review of the literature. Int Rev Psychiatry. 28,58-69.

Marshal, M.P., Dietz, L.J., Friedman, M.S., Stall, R., Smith, H.A., McGinley, J., Thoma, B.C., Murray, P.J., D'Augelli, A.R., Brent, D.A., 2011. Suicidality and depression disparities between sexual minority and heterosexual youth: A metaanalytic review. J Adolesc Health. 49(2),115-23.

McFarquhar, T., Luyten, P., Fonagy, P., 2018. Changes in interpersonal problems in the psychotherapeutic treatment of depression as measured by the Inventory of Interpersonal Problems: A systematic review and meta-analysis. J Affect Disord. 226, 108-123.

McLean, C.P., Asnaani, A., Litz, B.T., Hofmann, S.G., 2011. Gender differences in anxiety disorders: prevalence, course of illness, comorbidity and burden of illness. J Psychiatr Res. 45,1027-1035.

McNeil, J., Bailey, L., Ellis, S., Morton, J., Regan, M., 2012. Trans mental health and emotional wellbeing study. Edinburgh: Scottish Transgender Alliance.

Mendoza, C., Barreto, G.E., Ávila-Rodriguez, M., Echeverria, V., 2016. Role of neuroinflammation and sex hormones in war-related PTSD. Mol Cell Endocrinol. $434,266-277$. 
Mepham, N.J., Bouman, W.P., Arcelus, J., Hayter, M., Wylie, K.R., 2014. People with gender dysphoria who self-prescribe cross-sex hormones: prevalence, sources and side effects knowledge. J Sex Med. 11,2995-3001.

Meyer, I.H., 1995. Minority stress and mental health in gay men. J Health Soc Behav. 36, 38-56.

Meyer, I.H., 2003. Prejudice, social stress, and mental health in lesbian, gay and bisexual populations: Conceptual issues and research evidence. Psychol Bull. 129,674-697.

Meyer, I.H., Schwartz, S., Frost, D.M., 2008. Social patterning of stress and coping: Does disadvantaged social statuses confer more stress and fewer coping resources? Soc Sci \& Med. 67, 368-379.

Millet, N., Longworth, J., Arcelus, J., 2016. Prevalence of anxiety symptoms and disorders in the transgender population: A systematic review of the literature. Int J Transgenderism. 18(1), 27-38. DOI: 10.1080/15532739.2016.1258353.

Morton, L., Roach, L., Reid, H., \& Stewart, S.H., 2012. An evaluation of a CBT group for women with low self-esteem. Behav Cogn Psychother. 40,221-22

Mufson, L., Weissman, M.M., Moreau, D., Garfinkel, R., 1999. Efficacy of interpersonal psychotherapy for depressed adolescents. Arch General Psychiatry. 56, $573-579$.

Naslund, J.A., Aschbrenner, K.A., Marsch, L.A., Bartels, S.J., 2016. The future of mental health care: peer-to-peer support and social media. Epidemiol Psychiatr Sci. 25(2),113-122.

National Institute for Health and Clinical Excellence, 2009. Depression in adults: recognition \& management, http://www.nice.org.uk/guidance/cg90/chapter/4research-recommendations/. [accessed 01.01.2017]. 
Nemoto, T., Bodeker, B., Iwamoto, M., 2011. Social support, exposure to violence and transphobia, and correlates of depression among male-to-female transgender women with a history of sex work. Am J Public Health. 101(10), 19801988.

Nuttbrock, L., Hwahng, S., Bockting, W., Rosenblum, A., Mason, M., Macri, M., Becker, J., 2010. Psychiatric impact of gender-related abuse across the life course of male-to-female transgender persons. J Sex Res. 47(1),12-23.

Orre, C., Summanen, E., Hård, V., 2017. "In society I don't exist, so it's impossible to be who I am." - Trans people's health and experiences of healthcare in Sweden. The Swedish Federation for LGBTQ rights (RFSL). Retrieved on $9^{\text {th }}$ January 2018 from https://www.rfsl.se/wpcontent/uploads/2017/11/Trans health 2017 RFSL.pdf

Paykel, E.S., 1994. Life events, social support and depression. Acta Psychiat Scand. 89(s377),50-58.

Reisner, S.L., Vetters, R., Leclerc, M., Zaslow, S., Wolfrum, S., Shumer, D., Mimiaga, M.J., 2015. Mental health of transgender youth in care at an adolescent urban community health center: a matched retrospective cohort study. J Adolesc Health. 56,274-279.

Richards, C., Bouman, W.P., Seal, L., Barker, M.J., Nieder, T.O., T'Sjoen, G., 2016. Non-binary or genderqueer genders. Int Rev Psychiatr. 28,95-102.

Rigby, L.W., Waite, S. Group therapy for self-esteem, using creative approaches and metaphor as clinical tools. Behav Cog Psychother. 35, 361-364.

Rimes, K.A., Goodship, N., Ussher, G., Baker, D., \& West, E., 2017. Non-binary and binary transgender youth: Comparison of mental health, self-harm, suicidality, 
substance use and victimization experiences. Int J Transgenderism. Advance online publication. https://doi.org/10.1080/15532739.2017.1370627

Rohleder, N., Schommer, N.C., Hellhammer, D.H., Engel, R., Kirschbaum, C., 2001. Sex differences in glucocorticoid sensitivity of proinflammatory cytokine production after psychosocial stress. Psychosom Med. 63,966-972.

Rosenberg, M., 1965. Society and the adolescent self-image. Princeton, NJ: Princeton University Press.

Singh, A.A., Bower, K.L., 2017. Aging in transgender and gender nonconforming communities, in: Bouman, W.P., Arcelus, J., (Eds.). The Transgender Handbook: A guide for transgender people, their families, and professionals. New York, NY: Nova Publishers.

Sowislo, J.F., Orth, U., 2013. Does low self-esteem predict depression and anxiety? A meta-analysis of longitudinal studies. Psychol Bull. 139(1), 213-240.

Stordal, E., Mykletun, A., Dahl, A. A., 2003. The association between age and depression in the general population: a multivariate examination. Acta Psychiatr Scand. 107(2), 132-141.

van Caenegem, E., Wierckx, K., Elaut, E., Buysse, A., Dewaele, A., Van Nieuwerburgh, F., De Cuypere, G., T'Sjoen, G., 2015. Prevalence of gender nonconformity in Flanders, Belgium. Arch Sex Behav. 44,1281-1287.

van de Grift, T.C., Cohen-Kettenis, P.T., Elaut, E., De Cuypere, G.R.E.T.A., Richter-Appelt, H., Haraldsen, I.R., Kreukels, B.P., 2016. A network analysis of body satisfaction of people with gender dysphoria. Body Image. 17,184-90.

van de Grift, T.C., Cohen-Kettenis, P.T., Steensma, T.D., De Cuypere, G., Richter-Appelt, H., Haraldsen, I.R., Dikmans, R.E., Cerwenka, S.C., Kreukels, B.P., 
2016. Body satisfaction and physical appearance in gender dysphoria. Arch Sex Behav. 45(3),575-85.

Vocks, S., Stahn, C., Loenser, K., Legenbauer, T., 2009. Eating and body image disturbances in male-to-female and female-to-male transsexuals. Arch Sex Behav. 38,364-377.

Walls, N.E., Laser, J., Nickels, S.J., Wisneski, H., 2010. Correlates of cutting behavior among sexual minority youths and young adults. Soc Work Res. 34,213-226.

Warren, J.C., Bryant Smalley, K., Barefoot, K.N., 2016. Psychological wellbeing among transgender and genderqueer individuals. Int J Transgenderism. 17(34),114-123.

WHO. Depression Factsheet. //www.who.int/mediacentre/factsheets/fs369/ en/.2016 [accessed 02.09.2016].

WHO Mental Health Gap Action Programme (mhGAP). //www.who.int/mental_health/mhgap/en/. 2016 [accessed 21.12.2016]

Witcomb, G.L., Bouman, W.P., Brewin, N., Richards, C., Fernandez-Aranda, F., Arcelus, J., 2015. Body image dissatisfaction and eating-related psychopathology in trans individuals: A matched control study. Eur Eat Disord Rev.23(4),287-293.

Wylie, K.R., Barrett, J., Besser, M., Bouman, W.P., Bridgeman, M., Clayton, A., \& ... Ward, D., 2014. Good practice guidelines for the assessment and treatment of adults with gender dysphoria. Sex Relation Ther. 29,154-214.

Zeluf, G., Dhejne, C., Orre, C., Nilunger Mannheimer, L., Deogan, C., Höijer, J., Ekéus Thorson, A., 2016. Health, disability and quality of life among trans people in Sweden-a web-based survey. BMC Public Health. 16(1), 1-15.

Zigmond, A.S., Snaith, R.P., 1983. The hospital anxiety and depression scale. Acta Psychiat Scand. 67,361-370. 
Zimet, G.D., Powels, S.S., Farley, G.K., Werkman, S., Berkoff, K.A., 1990. Psychometric characteristics of the multidimensional scale of perceived social support. J Pers Assess. 55,610-617.

Zucker, K.J., Lawrence, A.A., 2009. Epidemiology of gender identity disorder: Recommendations for the Standards of Care of the World Professional Association for Transgender Health. Int J Transgenderism. 11,8-18. 


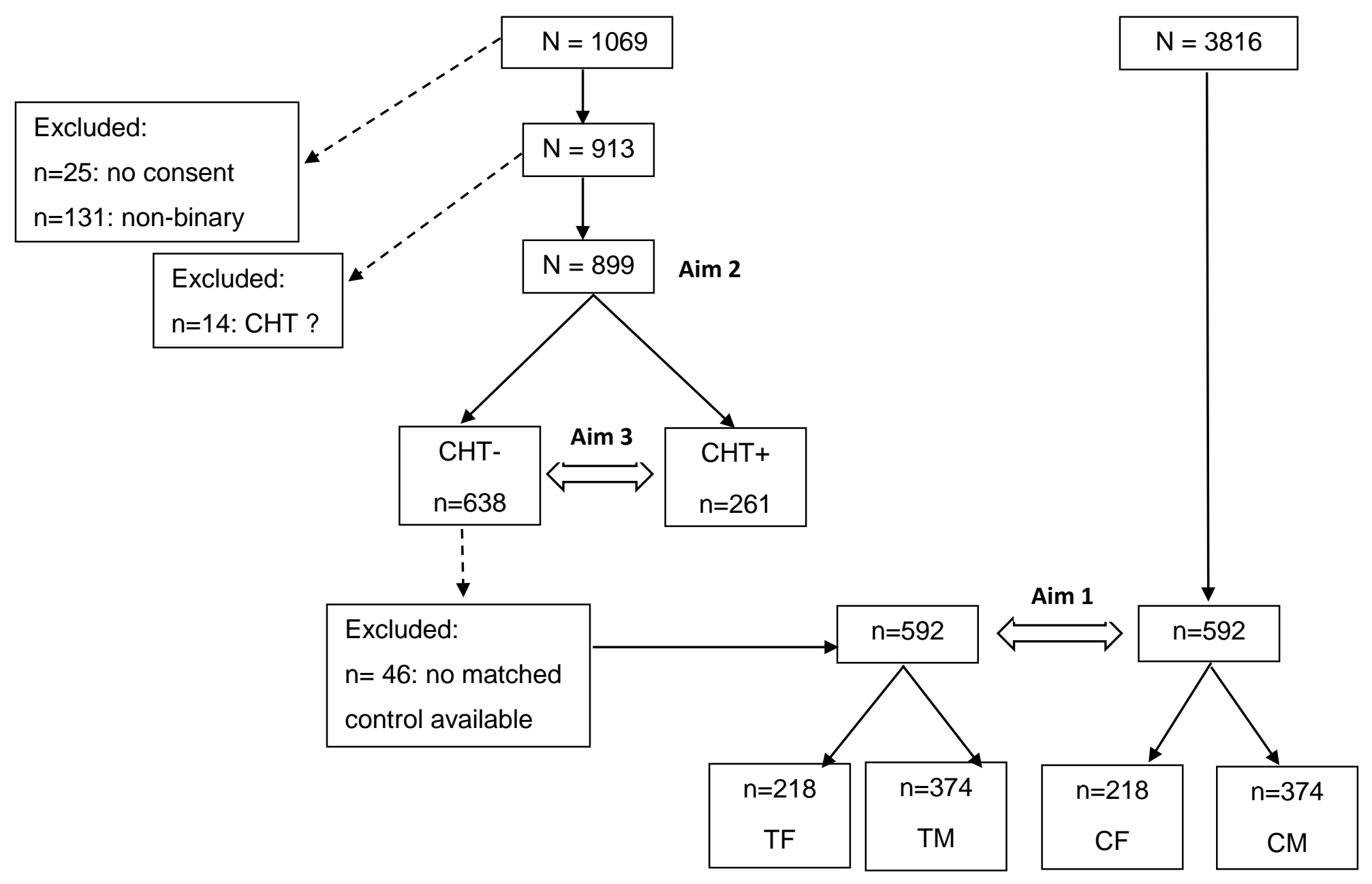

Figure 1: Diagram to show the cohorts for each aim of the study and the exclusions. 
Table 1: Number of transgender (TG) people and controls with no depressive disorders, and depressive disorders (possible and probable) ( $\mathrm{n}=1184$ )

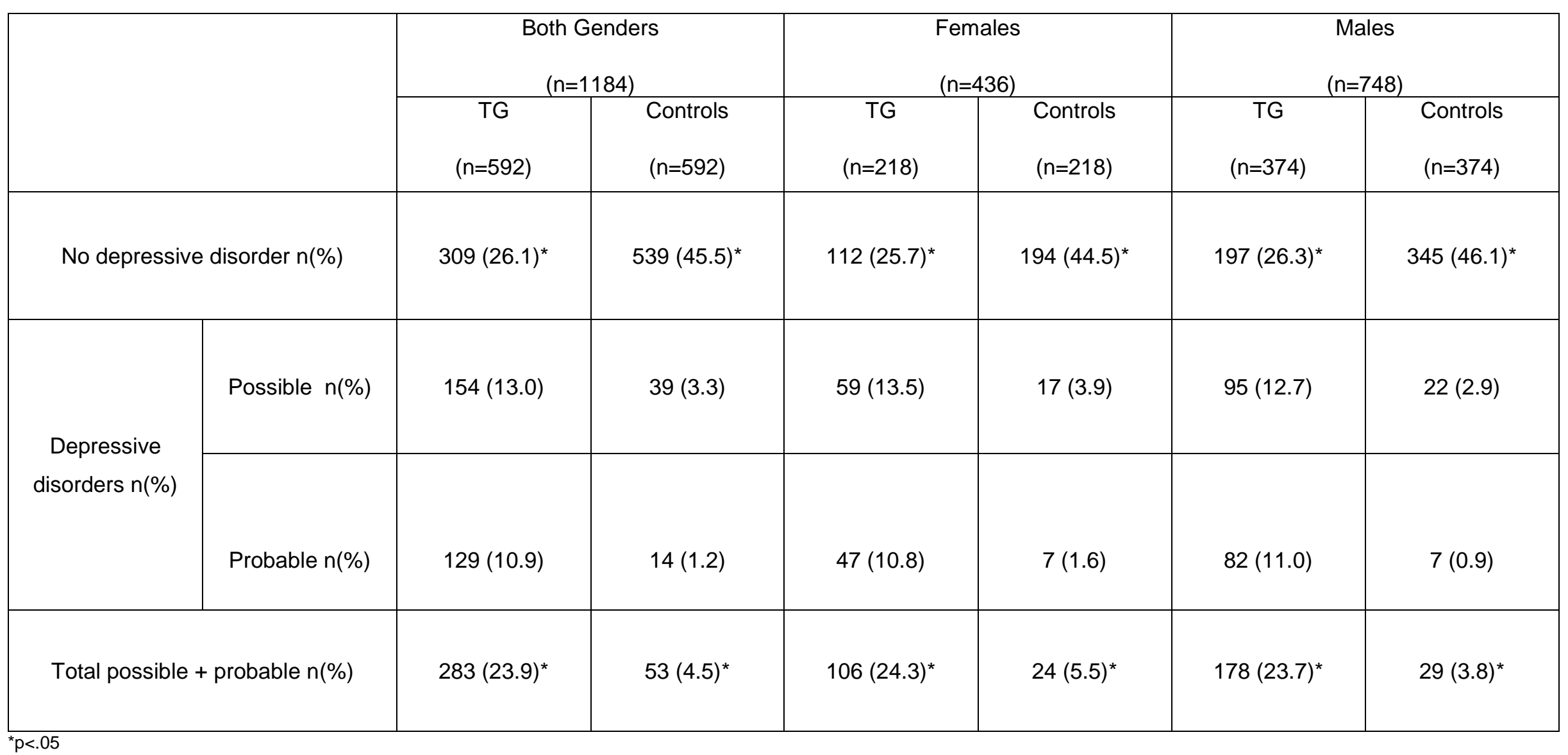


Table 2. Predictive role of age, gender, self-esteem, social support, interpersonal function and victimization in transgender people with possible and probable depressive disorder (as one category) compared to transgender people with no depressive disorder.

\begin{tabular}{|c|c|c|c|c|c|}
\hline & B & SE & Wald & $\operatorname{Exp}(B)$ & $\mathrm{p}$ \\
\hline Age & ,017 & ,008 & 5,028 & 1,017 & ,025 \\
\hline Assigned Gender & ,230 & 187 & 1,512 & 1,259 & ,219 \\
\hline $\mathrm{CHT}$ pre assessment &, 009 & 196 &, 002 & 1,009 & ,963 \\
\hline Global score MSPSS &,- 015 & ,006 & 6,257 &, 985 &, 012 \\
\hline Total RSE &,- 118 & 018 & 44,706 & ,889 &, 000 \\
\hline Global IIP score & ,911 & 163 & 31,149 & 2,488 &, 000 \\
\hline Total Transphobia &, 012 &, 035 & 112 & 1,012 &, 737 \\
\hline Constant & ,281 & ,622 & ,204 & 1,325 & ,651 \\
\hline
\end{tabular}

a. Dependent Variable: presence/absence of depression (HADS) 
Table 3. Depressive disorders based on the HADS in transgender people on cross-sex hormone treatment (CHT) and those not on cross-sex hormone treatment $(n=899)$

Transgender people not on $\mathrm{CHT}$ $\mathrm{N}(\%)$
Transgender people on CHT

$$
\mathrm{N}(\%)
$$

\begin{tabular}{|c|c|c|c|c|c|c|}
\hline & $\begin{array}{c}\text { All } \\
(n=638)\end{array}$ & $\begin{array}{c}\text { Transgender } \\
\text { males } \\
(n=247)\end{array}$ & $\begin{array}{c}\text { Transgender } \\
\text { females } \\
(n=391)\end{array}$ & $\begin{array}{c}\text { All } \\
(n=261)\end{array}$ & $\begin{array}{c}\text { Transgender } \\
\text { males } \\
(\mathrm{n}=81)\end{array}$ & $\begin{array}{c}\text { Transgender } \\
\text { females } \\
(n=180)\end{array}$ \\
\hline No depressive disorder (Score 0-7) & $334(52.4)$ & $125(50.6)$ & 209 (53.5) & $169(64.8)$ & $52(64.2)$ & $117(65.0)$ \\
\hline $\begin{array}{l}\text { Possible or probable depressive disorder (Score } \geq \\
\text { 8) }\end{array}$ & $304(47.6)$ & $122(49.4)$ & $182(46.5)$ & $92(35.2)$ & $29(35.8)$ & $63(35.0)$ \\
\hline
\end{tabular}

